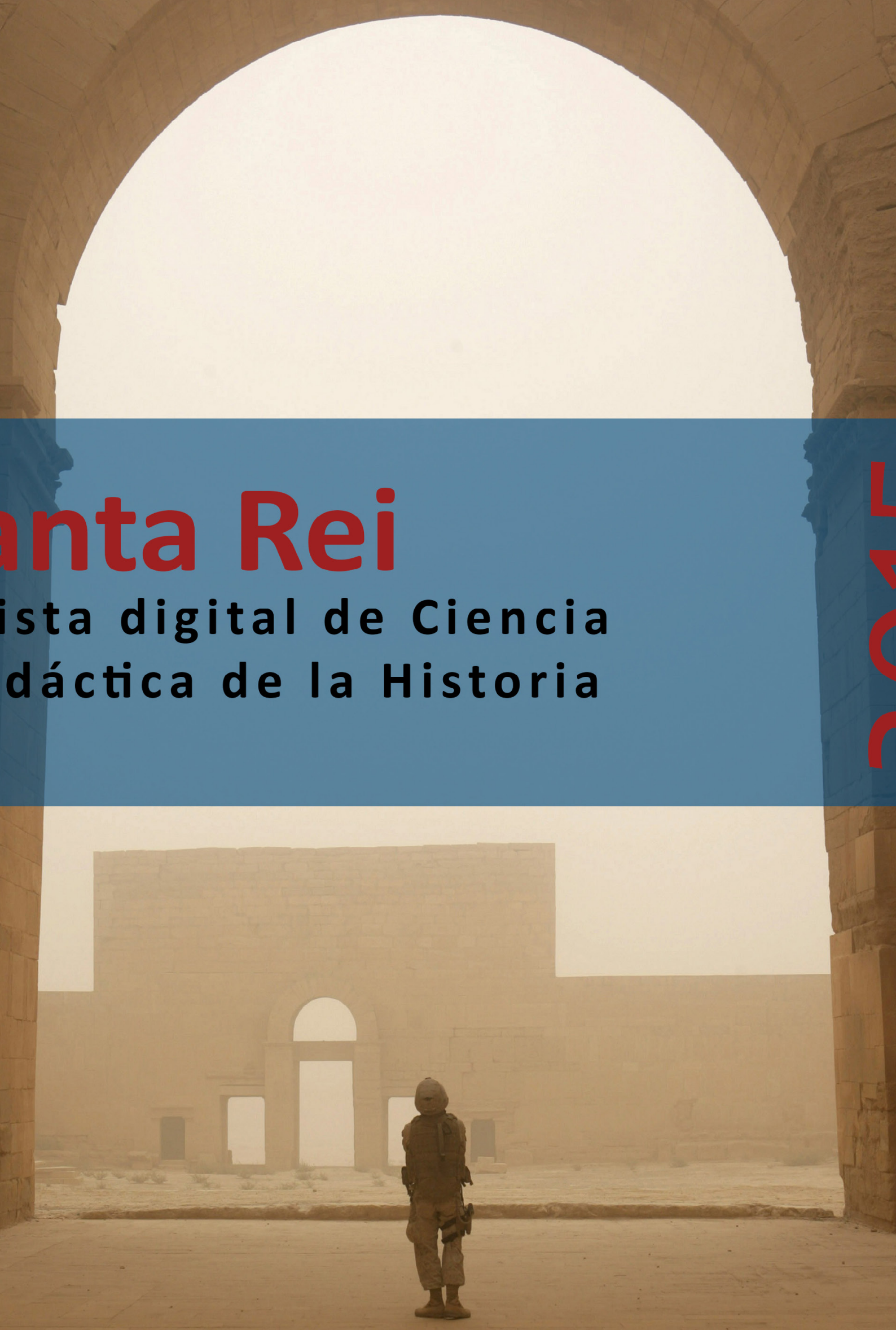

Revista digital de Ciencia y Didáctica de la Historia 


\section{Panta Rei \\ Revista Digital de Ciencia \\ y Didáctica de la Historia}

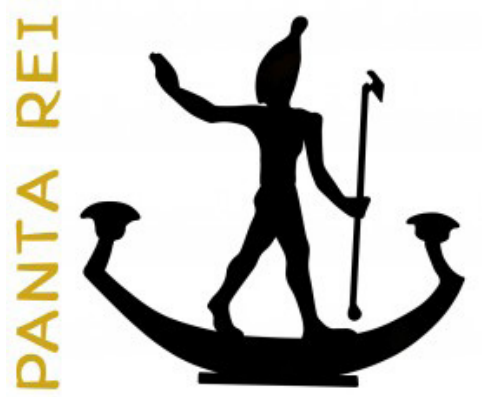

\section{5}

Revista anual

Fecha de inicio: 1995

Revista Panta Rei. pantarei@um.es

Edita:

Centro de Estudios del Próximo Oriente y la Antigüedad Tardía - CEPOAT

Edificio Universitario Saavedra Fajardo.

Universidad de Murcia

C/ Actor Isidoro Máiquez, 9

30007 - MURCIA - ESPAÑA

Teléfono: (+34) 868883890

cepoat@um.es

Web: www.um.es/cepoat/pantarei

Edición 2015

ISSNe: 2386-8864

ISSN: 1136-2464

Depósito legal: MU-966-1995
cepoAt

UNIVERSIDAD DE MURCIA centro de estudios del próximo oriente y la antigüedad tardía

En Portada: Ruinas de Hatra (Irak) (Fotografía de: Lance Cpl. Albert F. Hunt, U. S. Marine Corps).

Responsables de los textos: Sus autores.

Responsable de la presente edición: Consejo Editorial Panta Rei. 


\section{CONSEJO DE REDACCIÓN}

\section{Coordinador editorial}

Egea Vivancos, Alejandro

[Didáctica de las Ciencias Sociales, UMU]

\section{Editores}

Botí Hernández, Juan Jesús

[CEPOAT, UMU]

Meseguer Gil, Antonio José

[CEPOAT, UMU]

Sáez Giménez, David Omar

[CEPOAT, UMU]

Sánchez Mondéjar, Celso Miguel

[CEPOAT, UMU]

\section{Secretaria}

Arias Ferrer, Laura

[Didáctica de las Ciencias Sociales, UMU]

\section{Responsable informático}

Martínez García, José Javier

[CEPOAT, UMU]

\section{Traducción y corrección lingüística}

Martínez Martínez, Cristina

[Sociedad Española de Lenguas Modernas]

\section{CONSEJO ASESOR}

Albero Muñoz, M. ${ }^{a}$ del Mar [H. ${ }^{a}$ del Arte, UMU]

Chapman, Arthur

[History Education, UCL, Reino Unido]

Cobacho López, Ángel

[Derecho, UMU]

Egea Bruno, Pedro M. ${ }^{\text {a }}$

[Historia Contemporánea, UMU]

García Atienzar, Gabriel

[Prehistoria, UA]

González Monfort, Neus

[Didáctica de las Ciencias Sociales, UAB]

Haber Uriarte, María

[Prehistoria, UMU]

Irigoyen López, Antonio

[Historia Moderna, UMU]

Mahony, Simon

[Digital Humanities, UCL, Reino Unido]

Marsilla de Pascual, Francisco Reyes

[Técnicas historiográficas, UMU]

Miralles Maldonado, José Carlos

[Filología Clásica, UMU]

Molina Gómez, José Antonio

[Historia Antigua, UMU]

Noguera Celdrán, José Miguel

[Arqueología, UMU]

Pérez Molina, Miguel Emilio

[Filología Clásica, UMU]

Prados Martínez, Fernando

[Arqueología, UA]

Sánchez Ibáñez, Raquel

[Didáctica de las Ciencias Sociales, UMU]

Sancho Gómez, Miguel Pablo

[Educación, UCAM]

Vilar García, María José

[Historia Contemporánea, UMU] 

Artículos

El patrimonio arqueológico iraquí y su destrucción a lo largo del tiempo.

Fernando Espejel Arroyo.

Tacita Muta y el silencio femenino como arma del patriarcado romano.

Sara Casamayor Mancisidor.

Espartaco en la arqueología.

Juan Luis Posadas.

La batalla de Andagoste.

Luis Amela Valverde.

Las trabas para una formación arqueológica inclusiva.

Ana Samaniego Espinosa.

Repensando las narrativas nacionales: Un análisis del origen, transmisión e influencia en el aprendizaje histórico.

César López Rodríguez

El profesor como predicador, provocador y ermitaño. Un pre-texto para pensar las tareas de la didáctica de la historia.

Enrique Ibáñez Rojo

Entrevista

Evaluando el desarrollo de la competencia histórica en la enseñanza de la Historia en España. Entrevista a Jesús Domínguez Castillo.

María José Morales Rodríguez.

Reseñas

II Congreso de Jóvenes Investigadores del Mundo Antiguo de la Universidad de Murcia.

Pedro David Conesa Navarro y Juana M. ${ }^{a}$ Martínez Molina.

II Jornadas Internacionales de Didáctica de la Historia.

Eusebio Manuel Vidal Abellán.

Dölger, F. J. (2015). La luz de Cristo. Madrid: Ediciones Encuentro. 98 págs.

Alejandro Ruiz Sánchez.

Cooper, H. (ed.) (2013). Teaching History Creatively. Londres: Routledge. 185 págs.

Marta Gil de Sola Bellas.

El arte paleolítico en El Carnicero de Chabrol.

Alberto Lombo Montañés.

Normas de publicación/Publishing rules 



\title{
El profesor como predicador, provocador y ermitaño Un pre-texto para pensar las tareas de la didáctica de la historia
}

\author{
The teacher as a preacher, provoker and hermit. A pre-text to think on \\ the tasks of History didactics
}

\author{
Enrique Ibáñez Rojo' \\ Universidad Rey Juan Carlos
}

Recibido: 23/04/15

Aceptado: $11 / 06 / 15$

Para citar este artículo: Ibáñez Rojo, E. (2015). El profesor como predicador, provocador y ermitaño. Un pre-texto para pensar las tareas de la didáctica de la historia. Panta Rei. Revista Digital de Ciencia y Didáctica de la Historia, 93-107.

ISSNe: 2386-8864

DOI: http://dx.doi.org/10.6018/pantarei/2015/7

\section{Resumen}

La enseñanza de la historia está condenada a ser una cuestión controvertida, dado que trata esencialmente de la formación moral y política de los jóvenes en sociedades que son, y han sido siempre, culturalmente diversas. Este artículo defiende la utilidad del último escepticismo filosófico (o, si se prefiere, del relativismo "posmoderno") para repensar las tareas de la didáctica de la disciplina y componer una figura ideal del profesor de historia capaz de transmitir enseñanzas auténticamente relevantes para el progreso de la comunidad democrática y la educación de sus futuros ciudadanos.

\section{Palabras clave}

Historiografía, Epistemología, Relativismo, Teoría cultural, Didáctica de la historia.

\begin{abstract}
The teaching of history is bound to be controversial, since it is essentially moral and political education of young people in societies that are, and have always been, culturally diverse. This article advocates the usefulness of the latest philosophical scepticism (or, if you prefer, the "postmodern" relativism) to reconsider the tasks of the didactics of this discipline and to frame an ideal image of the history teacher capable of transmitting lessons that could be truly relevant for the advance of the democratic community and the education of its future citizens
\end{abstract}

\section{Key Words}

Historiography, Epistemology, Relativism, Cultural Theory, History Didactics

\footnotetext{
1 Para contactar con el autor: Enrique Ibáñez Rojo. Profesor Titular de Universidad. Dpto. de Historia e Instituciones Económicas y Filosofía Moral. Facultad de Ciencias Jurídicas y Sociales. Paseo Artilleros s/n. 28032. Madrid. enrique.ibanez@urjc.es
} 


\section{El sentido secular de la enseñanza de la historia}

El hecho de que "no haya comunidad humana que no sepa del pasado y que no se proyecte hacia el futuro", escribió hace un tiempo Savater, "es quizá el rasgo menos animalesco que hay en nosotros". Todas las comunidades humanas enseñan a cada uno de sus jóvenes que muchos de sus semejantes ya murieron y que sin embargo "sus descubrimientos o sus luchas siguen contando para él como lecciones vitales, lo mismo que otros aún no han nacido aunque ya le corresponde a él tenerlos en cuenta para mantener o renovar el orden de las cosas" (Savater, 1997, pp. 38-39). Proyectarse hacia el futuro, aprender lecciones vitales de los ancestros para mantener o renovar el orden de las cosas... En la lectura de Savater, si no interpreto muy mal sus palabras, el "saber sobre el pasado" que el grupo transmite a sus jóvenes es una narración cargada de moralejas y mensajes políticos. Un relato que les habla de quiénes son y quiénes deben ser. Una narración que les explica, en otras palabras, en qué consiste ser un miembro cabal de la comunidad en el lugar y el tiempo que les ha tocado vivir. Este es, según parece, el sentido secular de la enseñanza de la historia. Para eso se ha enseñado historia desde siempre y para eso sigue enseñándose hoy.

\section{Polémicas y más polémicas}

Claro que si decimos que no hay comunidad humana que no sepa de su pasado y se proyecte hacia el futuro, podríamos perfectamente traducir "saber" por "control" y "proyectar el futuro" por "cerrarlo" (bien para mantener el statu quo o para inducir un cambio, evolutivo o radical, en un sentido determinado). Sabemos, en efecto, que cualquier grupo instituido "bloquea la curiosidad personal, organiza la memoria pública e impone heroicamente la certeza sobre la incertidumbre" (Douglas, 1996, p.150). Pero también sospechamos que seguramente no haya grupo humano, desde el más grande al más pequeño, en el que reine un consenso perfecto sobre la mejor manera de organizar la vida en común. Por eso discutimos sobre la historia y las enseñanzas que cabe extraer de ella. Por eso no tenemos un único relato, consensuado o asumido por todos, sobre las peripecias de la comunidad humana a la que pertenecemos y nuestros deberes para con ella, sobre las obligaciones de los jóvenes de conservar lo más valioso de la herencia, renovarla, mejorarla o superarla para su beneficio y el de quienes vengan después. Ni siquiera hemos acordado de qué comunidad hablamos cuando decimos que pertenecemos a ella, ni sobre si el pasado nos impone alguna obligación en absoluto. Y no deberíamos pensar que en algún otro tiempo, oscuro o dorado, hubo una auténtica unanimidad al respecto. Seguramente nunca existió la legitimidad incuestionada y seguramente se ha discutido siempre sobre la historia, igual que lo hacemos hoy.

\section{3. ¿Con los mismos protagonistas?}

Y puede que los protagonistas de los debates también hayan sido en cierto modo los mismos desde el principio. Según la antropóloga Douglas, en todas las comunidades humanas han convivido siempre tres tipos de culturas o solidaridades "activas", en una dinámica siempre cambiante de correlaciones de fuerzas, conflictos y alianzas: el jerarquismo, el individualismo y el igualitarismo. Cada una de ellas está enraizada en una determinada estructura de interacción, un "estilo de vida" que promueve una manera peculiar de percibir o construir la realidad. Cada una contiene un "sesgo" cultural específico: concepciones del tiempo, de la naturaleza humana, la justicia, el riesgo, la culpa, el liderazgo y el gobierno, que son compatibles con el modelo de organización colectiva y lo sostienen. ${ }^{2}$ Cada una de ellas, para lo que aquí nos interesa, cuenta su propia historia legitimadora.

2 En realidad, su tipología incluye una cuarta cultura, el fatalismo, que, como puede suponerse, no es un cultura "activa". A la teoría que se ha ido construyendo en los últimos años a partir de la obra seminal de Douglas se la suele conocer sin más como "teoría cultural", aunque en ocasiones aparece como "teoría cultural del riesgo", "teoría de la racionalidad plural", "institucionalismo neo-Durkheimiano" o "análisis red- 
De manera que, si Douglas y sus discípulos están en lo cierto, deberíamos suponer que siempre ha habido jerarquistas deseando impulsar la memoria de los orígenes ancestrales de la comunidad, de sus patriarcas, linajes y tradiciones; individualistas recordando a sus héroes e intentando minimizar el peso muerto del pasado, porque la sociedad competitiva es la que tiene una memoria más corta y la que menos depende de ella; y, finalmente, sectas, grupos o movimientos igualitaristas honrando a sus mártires, relatando las brutales injusticias de las otras dos culturas e insistiendo en la obligación de recordarlas. Y podríamos imaginar, a continuación, que son exactamente esas mismas culturas las que siguen aquí con nosotros (porque nosotros "somos" esas culturas), debatiendo sobre la historia y sus enseñanzas. Que, a este respecto, no ha cambiado apenas nada.

\section{El arribo de la ciencia y su retórica}

En lo que sí se ha innovado, y mucho, es en las retóricas que las culturas emplean para cribar el pasado, promover el recuerdo de experiencias y relatos que son compatibles con la rectitud de sus imágenes y respaldan una visión de las cosas complementaria consigo mismas, y olvidar las que no lo son.

La historia, como "forma genérica de conciencia en la que la experiencia de uno mismo y de otros en un entorno más o menos lejano se transforma en símbolos que se intercambian", parece ser un universal humano (Dening, 1996, p. 36) ${ }^{3}$. Su encarnación en "disciplina" académica, con un conjunto de códigos y prácticas profesionales y la pretensión de estar construyendo un corpus de conocimientos científico sobre el pasado, es, sin embargo, un hecho bastante reciente, cuyo impacto, además, se ha circunscrito a las poblaciones relativamente "avanzadas" u occidentalizadas ${ }^{4}$. Pero entre nosotros, y desde entonces, la "ciencia" se fue convirtiendo en un referente inevitable, un artefacto retórico omnipresente en las debates que las culturas mantienen sobre la historia y sus enseñanzas.

Supongo que no resulta exagerado afirmar que, en general y durante largo tiempo, la retórica de la ciencia sirvió básicamente para legitimar la transmisión y el aprendizaje del linaje de los órdenes jerárquicos: la vieja historia, aún tan presente, de la comunidad ancestral y sus patriarcas, jalonada en Europa por la conocida sucesión de los fundadores de las naciones, defensores heroicos de sus esencias, infinitos reyes y militares, sus gestas y grandiosas derrotas. Esa narración se presentaba ahora, sencillamente, como el producto científico de un estudio riguroso de las fuentes.

Los historiadores más afines a la cultura individualista, por supuesto, pretendieron lo mismo, y el relato liberal (o whig) de la historia fue ganando terreno en la profesión a medida que avanzaba la sociedad del contrato. Bajo el amparo de la ciencia, fue introduciendo cada vez más sus enseñanzas en la "historia común" que respaldaba los órdenes institucionales de las sociedades más avanzadas: Orden y Progreso.

Pero también la cultura igualitaria hizo un uso intenso y eficaz de la retórica de la ciencia para avanzar sus relatos "sectarios" (negadores de la "historia común" que se iba configurando a cada momento al albur de la cambiante correlación de fuerzas entre las dos culturas siempre dominantes) con los valores correspondientes. Sus esfuerzos culminaron, como sabemos, con la consolidación y la creciente presencia académica de la "nueva historia" de la posguerra, fuertemente influida por el

grupo" (grid-group analysis). Las principales exposiciones generales son probablemente Douglas (1982), Thompson, Ellis y Wildavsky (1990) y Schwarz y Thompson (1990).

3 Aunque podría pensarse en un grupo radicalmente individualista que viviera casi sin historia, eludiendo por completo las servidumbres, legados, deberes y privilegios heredados del pasado. Tal vez sea en parte el caso de los sherpas, que no pueden mencionar el nombre de sus muertos ni, por lo tanto, construir genealogías de ningún tipo (según Thompson, 2008).

4 La bibliografía sobre este proceso, en los cien años que han transcurrido desde la aparición en 1911 del clásico de Fueter (consultado en su edición de 1953) hasta la publicación del esfuerzo por escribir una "historia global de la historia" que tengo delante ahora (Woolf, 2011), debe ser poco menos que infinita. 
marxismo, que hizo bandera de la crítica al "positivismo ingenuo" de sus rivales y de su pretensión de hacer una historia más científica: una que, "como todas las ciencias", ofrecía "explicaciones causales" de los procesos de cambio (Iggers, 1997, p. 4).

\section{Encontrando pajas en el ojo ajeno}

En el nuevo tiempo, con la retórica de la ciencia demarcando ya el terreno y definiendo las reglas del juego, los portavoces de cada cultura se entregaron a la tarea de denunciar los "sesgos" y anteojeras ideológicas (las "carencias científicas") de las historias ajenas. Lo primero que nos viene a la cabeza son las infinitas filípicas que, desde las culturas dominantes, denunciaron la impregnación de las interpretaciones del pasado por los prejuicios y propósitos políticos, parciales y presentes, en la obra de los historiadores marxistas. Sin duda acertaron en lo básico.

A mediados del siglo pasado, la polémica de las culturas parecía dirimirse, en el ámbito académico, entre quienes preferían atenerse a los métodos tradicionales de la disciplina y quienes apostaban por una historia más "teórica", vinculada a los problemas y los procedimientos de las ciencias sociales. Pero sólo hasta cierto punto, porque en realidad todas las culturas estaban presentes en cada uno de los bandos del debate sobre las teorías y los métodos. La nueva historia "ciencia social", en efecto, no contenía sólo los valores igualitarios de los socialismos. Sus narrativas de la "modernización" podían respaldar perfectamente la cultura individualista, con sus correspondientes enseñanzas y promesas de futuro. Y sus explicaciones "estructurales" podían muy bien sostener valores netamente jerárquicos. Es muy posible, por ejemplo, que la insistencia de Braudel en la larga duración no sólo tuviese bastante que ver con su interés en encontrar "estructuras" de identidad profundas que debían sobrevivir a la humillante derrota de 1940, sino tal vez también con su interés por demostrar que la sangre francesa no se había diluido desde la prehistoria y que entre sus paisanos y los inmigrantes no había fusión posible. Mientras tanto, en lado opuesto de la orilla metodológica, Elton, el paladín de la rigurosa "objetividad" de la historia "pura", radicalmente empirista, ajena a las ciencias sociales y libre de anteojeras teóricas, revelaba su intención de contraponer a la imagen del ascenso imparable de la libertad, que había, según él, entronizado la cultura individualista que impulsaba la historiografía "whig" el seno de la academia, su propia obsesión jerárquica con «la necesidad de controlar la libertad». Por lo menos en la misma medida que por el "respeto a los hechos", aquel bastión de la vieja buena historia estaba motivado por un "sesgo" cultural no examinado, que le llevó, como mostrara en su momento Stone, a interpretar los documentos del modo en que mejor avalaran su valoración política de las virtudes del orden jerárquico y el gobierno "fuerte" (Evans, 1997, pp. 192-193).

\section{Contra la ciencia}

De manera que los portavoces de todas las culturas, a ambos lados de la polémica sobre métodos y teorías, se especializaron en encontrar las pajas que cegaban el ojo del antagonista y en recetarle más y mejor ciencia para despejar la vista. Gran éxito en el diagnóstico, porque todos estamos realmente cargados de prejuicios culturales. Pero fracaso rotundo en la terapia, porque nadie los ha superado hasta la fecha a base de ciencia.

En las últimas décadas del siglo pasado, sin embargo, se fue produciendo un cambio muy llamativo en la relación entre los discursos culturales sobre la historia y las retóricas de la ciencia. La principal novedad, como sabemos, estriba en que la cultura igualitaria (aunque no sólo ella) comenzó a utilizar preferentemente una retórica anti-científica para sostener sus relatos. En lugar de arrojar la ciencia a la cabeza del contendiente, se dedicó a disparar contra la ciencia misma, intentando cambiar las reglas del debate sobre la legitimidad de las historias que se escriben y se enseñan. 
Si tuviéramos que apostar, seguramente lo haríamos por buscar las razones básicas de esa mutación más en los cambios materiales que ha traído la historia misma, como mero paso del tiempo, que en el orden de las ideas. Porque las ideas, en efecto, no son nuevas: de un modo u otro, tanto ellas como buena parte de las palabras del nuevo relativismo "posmoderno", habían estado circulando por ahí desde mucho tiempo atrás ${ }^{5}$. Pero tal vez sea mejor imaginar que el último escepticismo filosófico y fenómenos como el naufragio de la utopía comunista o la emergencia de nuevas solidaridades igualitarias, más o menos ajenas al mundo del trabajo y con temáticas, agravios y reivindicaciones nuevas (género y orientación sexual, ecologismo, reconocimiento identitario, justicia retrospectiva), se han ido reforzando y alimentando mutuamente, añadiendo argumentos al relativismo y razones para ampararse en él a los portavoces de la cultura igualitaria en la academia. Pero el hecho, sean cuales sean las razones, es que en nuestro tiempo, después del marxismo, el igualitarismo tiende a no defender sus causas prometiendo "más ciencia", sino arremetiendo contra ésta: dirigiendo sus baterías contra las credenciales científicas de las "historias oficiales" que respaldan los órdenes institucionales vigentes.

\section{Hegemonías}

En cualquier sociedad, como dije, circulan relatos diversos sobre el pasado y sus "lecciones". Pero es indudable que en cada una de ellas y en cada período histórico predomina un estilo determinado de memoria pública. Y los portavoces de la cultura igualitaria en elámbito de la enseñanza tienen sin duda buenas razones para sostener que vivimos, aquí y ahora, como ha ocurrido siempre, en una situación marcada por el dominio de una narración "hegemónica" que tiende a ahogar las versiones que la contradicen: otros relatos, otras memorias cargadas de otras enseñanzas, otras obligaciones y otros valores. Algunos querrían añadir a esto, desde los escombros del "gran relato" marxista, que esa historia característica de nuestro tiempo se ajusta, por supuesto, a los intereses de la "clase dominante". En la jerga que estoy utilizando en estas páginas, tal vez diríamos que lo más razonable es esperar siempre que la cultura dominante legitime el tipo de organización social predominante, que no sería estable si no recibiese el apoyo ideológico de un número suficiente de los miembros de la comunidad. La "teoría cultural" de Mary Douglas supone que en cualquier comunidad habrá "una disputa continua tanto sobre la forma de organización como sobre la cultura que la sostiene". Pero constata, a la vez, que "el individualismo y el jerarquismo son las culturas que normalmente la dominan" (Douglas, 2003, pp. 1349 y 1370). Que alguna combinación variable de una y otra estará detrás de las "historias oficiales" que se relatan y enseñan. Ambas son aliadas y rivales al mismo tiempo: no hay mercado sin estado, ni libertad sin orden jerárquico. Cada una necesita en último término de la otra, dado que cada una hace algo vital que la otra no puede hacer por sí misma.

Lo anterior podría explicar el hecho, aparentemente paradójico, de que, aunque en las últimas décadas sea la cultura individualista la que haya ido imponiéndose sin discusión en la "batalla de las ideas" y dominando abrumadoramente en el mundo social, la enseñanza de la historia haya continuado siendo básicamente un baluarte del polo jerárquico de la ecuación. El orden es lo que la jerarquía ofrece al mercado, y el viejo relato de la comunidad ancestral y sus patriarcas, desde Numancia a los padres de la Constitución, es básicamente eso: una historia de orden. Porque los grandes aliados de la enseñanza escolar de la historia han sido siempre los Príncipes de Gales y no

5 Se ha puesto de moda, por ejemplo, hablar del "perspectivismo" inevitable en la interpretación de la historia, pero la palabra (y en buena medida la idea) es todo menos nueva: "El término perspectivismo fue forjado por Teichmüller (Cfr. Die wirkliche und die scheinbare Welt, 1882) para significar la posibilidad de considerar una cosa y, en general, el mundo, desde diversos puntos de vista, todos ellos justificados, de tal modo que cada punto de vista ofrezca una perspectiva única y a la vez indispensable acerca del universo" (Ferrater, 1965, pp. 406-407). Me interesa destacar, además de la fecha de acuñación del término, lo de "todos ellos justificados" $\mathrm{y}$ esa posibilidad sugerida de que todas las perspectivas resulten "indispensables" para abordar los problemas. 
los Andrew Carnegie de este mundo, que tienden a creer que no la necesitan y que normalmente no tienen paciencia para esas paparruchas ${ }^{6}$. Cuando Drucker, el maestro de la dirección de empresas, escribió sobre la educación para la "sociedad del saber", no pudo encontrar un lugar digno para la enseñanza de la historia: dio por sentado que se trata sólo de un triste "aprendizaje de hechos históricos" que habría que asignar de inmediato a un programa de ordenador para permitir que el profesor dedique su tiempo a cosas más importantes (Drucker, 1993, p. 197).

No debería extrañarnos, por lo tanto, que la consecuencia principal del avance continuo del contrato como base de la organización social y de la cultura individualista que lo acompaña y legitima, haya sido, al parecer, más el encogimiento de la historia escolar, su creciente irrelevancia, que cualquier cambio significativo en los contenidos o en los métodos de su enseñanza. Porque son las otras dos culturas, más colectivistas, las que otorgan un mayor valor al legado del grupo o la comunidad e insisten en las obligaciones y deberes heredados de las luchas, las injusticias o los logros del pasado. Son ellas las que tienden a implicarse más los debates sobre la transmisión de la historia. Por eso solemos percibir esos debates como un enfrentamiento a dos bandas entre los proyectos de revivir la tradición jerárquica y los impulsos subversivos de una cultura igualitaria siempre al margen del "bloque hegemónico", siempre radical e indignada.

\section{Diseminar el conocimiento incómodo}

Es evidente que ni las razones que alimentan el conflicto cultural que subyace al debate sobre la enseñanza de la historia, ni la fuerza de las partes contendientes, han cambiado o cambiarán por el hecho de que la nueva retórica "relativista" se difunda o retroceda. La nueva retórica no debilita los compromisos básicos de nadie, ni beneficia en principio a unos u a otros. El relativismo "sólo" aporta sinceridad y humildad a los debates. Por eso es un conocimiento incómodo que solemos despreciar, caricaturizándolo en el "modo Sokal" o rechazándolo airados desde las almenas que coronan la muralla de la virtud científica. Pero por ello es también un conocimiento enormemente valioso. No trabaja para nadie en particular, pero podría beneficiarnos a todos. Porque sin sinceridad, una de las dos "virtudes de la verdad" (la otra es la precisión), no hay manera de entenderse. Y porque la humildad es una condición necesaria para que, si fuera posible, alguna vez aprendiéramos algo conversando. ${ }^{7}$ Seguramente no voy a cambiar mis compromisos básicos por escucharte, pero si me explicas con sinceridad tus razones (en lugar de arrojarme la ciencia a la cabeza) y tengo la humildad necesaria para atenderlas (porque no estoy seguro de tener la ciencia yo), tendremos una conversación potencialmente más fructífera y, desde luego, mucho más agradable. De modo que podemos elegir entre seguir jugando, como niños prepotentes, a arrojar al adversario, una y otra vez, las pedradas de la ciencia, o comenzar a hablar como adultos. Mejor intentar lo segundo.

Propongo, por lo tanto, como primera tarea para todos los interesados en la historia y su enseñanza, hacer un uso contundente y "didáctico" de los argumentos del escepticismo filosófico para ir cegando las cuevas donde se refugian quienes aún pretenden que lo que proponen enseñar

6 El Príncipe de Gales no deja de lamentar el olvido de la valiosa herencia británica y se ha empeñado recientemente en convocar a las estrellas más rutilantes del firmamento historiográfico anglosajón (Starkey y Ferguson, con Schama en el papel de disidente) para ayudarle a apuntalarla en las escuelas. Por su parte, Carnegie, el magnate del acero, inauguró a finales del siglo XIX la ofensiva del empresariado norteamericano (en muchos sentidos la representación más pura de la cultura individualista) contra unos estudios humanísticos cuajados de historias de gentes muertas que sólo preparaban a los jóvenes "para la vida en otro planeta" (Donoghue, 2008, p. 4).

7 Amèlie Oksenberg Rorty escribió hace un tiempo que la vida intelectual depende de "la capacidad para implicarse en una conversación continua, probándonos unos a otros, descubriendo nuestros presupuestos ocultos, cambiando de idea porque hemos escuchado las voces de nuestros contertulios". Los lunáticos (si alguien quiere, puede imaginar, por ejemplo, a Pío Moa) también cambian de ideas, pero sus ideas cambian con los movimientos de la Luna, no porque hayan escuchado, realmente escuchado, las preguntas y las objeciones (McCloskey, 2001, p. 515). 
es, sin más, aquello que impone el estudio riguroso del pasado "propiamente dicho". Sabemos que ese discurso cientifista sigue, por desgracia, vivo y bien. Pareciera incluso que el triste estado de las ciencias sociales ${ }^{8}$ y el colapso de la ambiciones integradoras de sus grandes paradigmas explicativos (por no hablar del destino de la "ciencia del hombre" en cuya construcción quisieron embarcar al historiador los primeros annalistes) les ha dado nuevos bríos. Algunos, en efecto, han saltado del barco de la "nueva historia" sucumbiendo a la tentación de retornar a la narración sin pretensiones teóricas que, según dicen, se limita a contar las cosas "tal como fueron". Y mientras unos están de vuelta, los que nunca abandonaron el refugio del empirismo más crudo reivindican ufanos su presciencia, alegando que "siempre lo supieron", que ya nos habían avisado de que la complejidad de la materia histórica escapa por completo a la ambición generalizadora de las teorías. Así que conviene diseminar el conocimiento incómodo. Intentar que todos ellos se den por aludidos, que se enteren de una vez de que no sólo han encallado las "grandes narrativas" que empleaba hasta hace poco (preferentemente, aunque no sólo) la cultura igualitaria. Que entiendan que resulta completamente irrelevante si uno utiliza teorías sobre la "elección racional", las "estructuras", los "grupos de status" o las "clases" socio-económicas, o se imagina más bien descubriendo sin más en las fuentes las huellas de un pasado susceptible de ser "correctamente" reconstruido tras un trabajo hermenéutico bien hecho. Que, al final, se trate del historiador-sujeto-autor de la historia "vieja" o el historiador-portador de lenguajes teóricos de la "nueva", todos transmiten a la postre con sus narraciones un mensaje político y moral, consciente o inconscientemente. Un mensaje que es el suyo o, más bien, el de su tiempo y su cultura? ${ }^{\text {. }}$

8 ¿Acaso es posible compartir de verdad el limpio entusiasmo que expresaba todavía hace poco Runciman (1999, p. 10) con los progresos de una ciencia social crecientemente capaz de producir "explicaciones que no hay más remedio que aceptar en la medida en que la evidencia excluye cualquier alternativa posible"? Porque no es sólo que no podamos encontrar "todavía" esas explicaciones en los textos, sino que tampoco hay modo de detectar progreso acumulativo alguno: en realidad, las ciencias sociales parecen haber tomado el camino inverso, deviniendo cada vez más "multiparadigmáticas", lo que no es sino un modo aséptico e indoloro de decir que su estado es espantosamente caótico. Sobre el estado de la ciencia social, marcado por "una conciencia generalizada de fracaso", puede verse el prólogo de Antoni Doménech (Hollis, 1998).

9 Farrell (1996) explicó muy bien cómo nuestras soluciones al problema de la "objetividad" (la vía racionalista y la empirista) proceden de una misma autoconcepción del sujeto moderno que adoptó "el punto de vista de Dios", siguiendo dos estrategias alternativas que lo separaban por caminos diferentes del mundo circundante y terminaban siempre "encogiendo" a éste: reduciéndolo bien a una proyección de las categorías teóricas del sujeto, bien a un conjunto de datos empíricos discretos. Y el hecho es que la reflexión filosófica en la segunda mitad del siglo $\mathrm{XX}$ ha ido desmontando progresivamente esa imagen del sujeto y de su relación con el mundo: mostrando, por un lado, hasta qué punto la teoría está siempre implicada en la percepción de los datos, de modo que el registro pasivo que exige el empirismo es una entelequia; y, por otro, que no existe esa unidad del sujeto que exigía Kant y necesita el racionalismo, porque no hay lenguaje teórico con valor de verdad universal, sino una diversidad de lenguajes culturales. La filosofía contemporánea, por lo tanto, ha impulsado un doble movimiento de inmersión de sujeto en el mundo que ha socavado radicalmente nuestras pretensiones de "objetividad". Si esto es así, se trata de una saludable cura de realismo y, con ello, de humildad. Conviene, de paso, recordar que los dardos de los filósofos iban preferentemente dirigidos a las ciencias naturales, aunque sólo hayan afectado a las sociales. Esto no debería extrañarnos si pensamos que las primeras pueden ampararse sin más en un criterio pragmático: sencillamente, funcionan. Las sociales, no. Hobsbawm (1998) recordaba al respecto que no ha habido ningún ataque ludita digno de mención contra las radios o las aspirinas, pero que en absoluto hay "discursos sociales" cuya utilidad resulte tan evidente y neutra desde el punto de vista normativo como para ser aceptada de modo universal. Por eso resulta chocante que los mejores manuales de filosofía de las ciencias sociales se limiten a atacar el relativismo remitiéndose al tipo de razones prácticas a las que esas ciencias difícilmente pueden apelar: se nos dice, por ejemplo, que la "prueba" contra el relativismo es que la gente confluye en una "verdad" determinada porque nadie quiere que sus canoas se hundan o sus hijos mueran de malaria (Little, 1991). Pero, ¿qué tiene que ver esto con nosotros? ¿Acaso se puede esperar que descubramos una vacuna contra la malaria o que enseñemos a los vecinos a construir canoas más sólidas? 


\section{El relativismo no nos divide}

Además, no hace falta leer y creer a los "posmodernos" para admitir de una vez que cuando discutimos sobre la historia y su enseñanza conversamos sobre nuestras morales al menos en la misma medida en que lo hacemos sobre las "verdades" del pasado. Debería bastar con volver a leer a Danto (1989). O con seguir al último Williams (2006), que no cita a Danto, en su elocuente defensa de las virtudes de la verdad, hasta que llega, en el último capítulo, a la narración histórica. Para entender que no se trata sólo de que todas las narraciones históricas implican una selección de los hechos a partir de algún criterio de relevancia que es nuestro (y, por lo tanto, plural), sino que los mismos hechos tienen, además, un sentido diferente para los distintos públicos. No podemos contar toda la historia, de modo que el pasado "propiamente dicho" o no está en ninguna parte o está en más de una. Sí podemos, desde luego, contar historias sin sentido, sin enseñanzas, lecciones ni moralejas (una maldita cosa detrás de la otra, tal vez aclarando, en la medida de lo posible, cómo de una cosa se pasó a la siguiente). Aunque si lo hacemos seguro que el público se aburrirá pronto y se marchará a escuchar cosas más interesantes.

Pero lo que me interesa señalar aquí es que ese reconocimiento de la pluralidad no nos condena a multiplicar las historias de un modo que haga imposible que lleguemos a alcanzar un acuerdo sobre la enseñanza de un pasado "común", en el caso de que lo consideremos necesario. El conocimiento incómodo del relativismo no nos divide: simplemente, nos explica por qué estamos divididos y nos avisa de que la apelación a la ciencia no va a resolver nuestras diferencias. Y, aunque hay muchas historias en la historia, es evidente que no todas son igualmente importantes para nosotros.

En sus últimos años, Judt expresó una clara nostalgia por aquella enseñanza tradicional que, "por selectivo que fuera su enfoque (...), al menos tenía la ventaja de proporcionar a una nación referencias pasadas para su experiencia presente", contribuyendo así a generar "una cultura común" cuya desaparición pone en peligro "el futuro del gobierno democrático" (Judt, 2008, pp. 16-17). No dudo de que sus palabras estaban, como casi siempre, cargadas de razón, y de que es muy probable que tengamos muy buenos motivos para esforzarnos en conservar y reforzar la enseñanza de una "historia común". Seguramente es, además, una empresa factible, porque es mucho lo que puede unirnos. Aunque los conflictos entre las culturas están hoy, tras las pesadillas del pensamiento único, tan vivos como siempre, todos hemos cambiado lo suficiente como para imaginarnos formando parte de un "nosotros" con algunas creencias y compromisos compartidos que nos diferencian de los "otros" que fuimos en el pasado. Unas creencias y unos compromisos que deberían permitirnos reconocer logros, avances, conquistas, hitos que podrían sostener una narrativa básica de progreso que nos inspire a defender lo que hemos conseguido y que merezca la pena enseñar a los jóvenes. Esta es, pues, la segunda tarea que propongo para la didáctica de la historia: trabajar para reelaborar nuestra "historia común" en el tablero transparente y amable que ofrece el relativismo. Un tablero en el que no está permitido confundir, agredir ni asustar a los contertulios convocando al espectro de la verdad científica, o, lo que es lo mismo, pretendiendo, como, lamentablemente, hace el propio Judt, que uno ha descubierto, tras arduo estudio, "la forma narrativa propia del pasado" (Judt, 2008, p. 16).

\section{Adoctrinar y debatir}

De manera que la "historia común" puede ser una construcción reflexiva (y más o menos democrática, abierta y sensible a todas las voces) o imponerse en nombre del conocimiento científico del pasado y el acceso privilegiado a su "forma narrativa propia". Pero la enseñanza de la "historia común" será, siempre y en cualquier caso, una operación de adoctrinamiento. Una operación de adoctrinamiento que podríamos considerar necesaria y valiosa si fuese cierto que todo orden institucional requiere una historia legitimadora y si creemos que el nuestro contiene 
elementos muy estimables que merece la pena intentar conservar ${ }^{10}$. $\mathrm{Y}$ bastaría para ello con que compartiésemos con Nussbaum la idea genérica de que "los jóvenes de todo el mundo, de cualquier país que tenga la suerte de vivir en democracia, deben educarse para ser participantes en esa forma de gobierno", dado que "ninguna democracia puede ser estable si no cuenta con el apoyo de ciudadanos educados para ese fin" (Nussbaum, 2010, p. 29). Si tenemos razones para suscribir esas palabras, las tendremos también para pensar que podemos y debemos enseñar (o adoctrinar a los jóvenes con las lecciones de) una "historia común".

A partir de este punto, sin embargo, comienzan las diferencias, porque cada una de nuestras culturas compone una figura diferente del "buen ciudadano" de la democracia. O, repitiendo lo que escribí al comienzo de este texto: cada una tiene su propia narración para explicarnos en qué consiste ser un miembro cabal de la comunidad en el lugar y el tiempo que nos ha tocado vivir. De modo que el profesor en la escuela democrática seguramente debe enseñar una historia inspiradora y persuasiva para cerrar un debate (el valor de la convivencia democrática), intentando, en palabras de Douglas (1996, p. 150), "imponer heroicamente la certeza sobre la incertidumbre" (o sea, para preservar esa convivencia). Pero, si quiere dar sentido a las clases de historia como un auténtico foro para la formación de la ciudadanía democrática (y esto es lo que repetimos una y otra vez cuando nos obligan a defender el valor de la enseñanza de la historia), debe también abrir un debate entre las distintas perspectivas sobre el "significado" o las "lecciones" del pasado. Habrá entonces que seleccionar un "ramillete de historias" para debatir en clase. Y esta es la tercera tarea que propongo para elaborar una didáctica útil de la historia.

\section{1. $Y$ tampoco hay tantas perspectivas}

Tendremos que seleccionar historias (esto también solemos repetirlo) que nos hablen sobre "problemas sociales relevantes del presente" (Cuesta, 2007, p. 59). Los problemas están en el debate público, no en la cabeza de cada uno de nosotros, de modo que no sería imposible que nos pusiésemos de acuerdo para elaborar una lista. Pero las historias que nos hablan sobre ellos están también en la sociedad que habitamos. "Es necesario que quede bien claro", escribió hace un tiempo Postman, "que las escuelas no están ni nunca estuvieron organizadas bajo el propósito de crear narrativas poderosas e inspiradoras: su función consiste en reunirlas, amplificarlas, ennoblecerlas y difundirlas" (Postman, 1999, p. 75). Y no hay tantas "narrativas inspiradoras y poderosas", o tantas "perspectivas" relevantes, sobre cada uno de nuestros problemas.

Si estuviésemos dotados de una racionalidad única (si fuésemos todos, todo el tiempo y en todos los contextos, por ejemplo, los "actores racionales" de la economía ortodoxa), habría sólo una perspectiva y sólo una historia verdadera para iluminar cada problema. Si fuésemos irracionales, cada loco contaría la suya: esta es la pesadilla que nos describen cuando quieren avisarnos de los "peligros del relativismo". Pero si (como nos dice la "teoría cultural" de Douglas y buena parte de la teoría social) la racionalidad es "contextual" y los contextos que confieren racionalidad a nuestras imágenes del mundo son limitados, podríamos decir "racionalidades", en plural, y esperar encontrar un número definido y recurrente de historias, cada una con sus propias "enseñanzas", sobre cada uno de nuestros problemas.

Si tratamos, por ejemplo, un problema histórico con tanta "relevancia" para nuestro presente como la emergencia de la gran empresa capitalista a finales del siglo XIX (con la consiguiente concentración de riqueza y poder), tendremos una historia individualista sobre "las virtudes del pacto burgués" (tú respetas mi libertad y me dejas que me haga rico y yo te hago rico a ti), otra historia jerarquista sobre "los peligros de la anarquía" (la importancia de controlar el mercado para

10 Me temo que los extremos "puros" de los cuadrantes en que habitan las culturas igualitarista y jerárquica (y probablemente también la individualista) contienen relatos que son incompatibles con la convivencia democrática, porque rechazan sus fundamentos mínimos o limitan nuestra responsabilidad cívica a armar una revolución. No podrían, por lo tanto, contenerse en ninguna "historia oficial" que sustente esa convivencia. 
evitar abusos, sobre el valor de la autoridad y el saber experto); y, finalmente, una igualitarista sobre "Ios pecados del capitalismo" (todos la conocemos, porque es la que más veces hemos contado: para el igualitarista, la justicia es la virtud primordial, como el orden lo es para la jerarquía y la libertad para el individualista). Si contamos la historia, tanto o más "relevante" para nuestro debate contemporáneo, del impacto medioambiental de nuestras actividades sobre la naturaleza, podremos reconocer y debatir un ramillete de relatos muy parecido. Encontraremos la historia individualista que nos explicará, con abundantes ejemplos, que la creatividad humana en una sociedad libre soluciona todos los problemas (la naturaleza es benigna), el relato jerárquico que nos enseñará que la virtud está en el respeto al saber experto y las reglas que dimanan de él (la naturaleza es tolerante dentro de unos límites), y, finalmente, el igualitario, que hablará de cómo la explotación comercial de la naturaleza y el despilfarro del capitalismo industrial nos han llevado al borde del desastre (la naturaleza es frágil y efímera). Cada una tiene su propio escenario (con sus supuestos básicos), unos villanos (los problemas a enfrentar), unos héroes (el empresario innovador, el sabio, el austero militante) y una moraleja (la "solución" apropiada).

Por supuesto, todas las tipologías tienen mucho de artificioso y no tenemos por qué buscar en cada caso el mismo patrón de historias culturales. Seguro que hay, además, otras propuestas que, con más o menos variaciones, pueden ayudarnos a "restringir el relativismo" (Verweij, 2007). En cualquier caso, necesitamos elaborar alguna tipología básica que nos permita ir más allá de la afirmación genérica de que tenemos "perspectivas diversas". Que nos ayude a seleccionar y llevar al aula un conjunto manejable de historias relevantes, interesantes y educativas, para debatir. Esta, como apunté arriba, podría ser nuestra tercera tarea.

Es importante que tengamos claro que las historias que nos interesan son las historias "ideologizadas", las que proponen respuestas, siempre "sesgadas", a nuestros problemas, participando en los debates públicos. Lo que hagan y discutan los historiadores profesionales es algo que debe preocupar, por supuesto, a quienes se interesan por la didáctica de la historia, pero no puede definir su agenda. Si en la disputa sobre la historia común nos convenía desarmar con una mirada irónica a todos los guardianes profesionales del pasado "propiamente dicho" y su "estructura narrativa propia", aquí tenemos que distinguir claramente entre los "problemas" de la historiografía y los que nos interesa abordar en el aula. Porque la historia escolar no puede ser, en ningún caso, una mera extensión o adaptación de la historia académica: como dejó dicho Habermas, el "uso público" de la historia (y su enseñanza es, por supuesto, una parte fundamental de él) es algo demasiado importante para dejarlo en manos de los historiadores.

\section{Pese a todo, el relativismo resulta incómodo}

Al parecer, Bohr dijo en una ocasión que "lo contrario de una declaración correcta es una declaración incorrecta, pero lo contrario de una verdad profunda es otra verdad profunda". Lo citaba Neil Postman en El fin de la educación, y añadía:

Con ello intentaba decirnos, al igual que otros sabios, que es preferible tener acceso a más de una verdad profunda. Ser capaz de mantener en mente la validez y utilidad de dos verdades contradictorias es fuente de tolerancia y -lo que es aún más importante- sentido del humor, que es a su vez el mejor antídoto contra el fanatismo.

(Postman, 1999, p. 23)

"Nunca se pondrán de acuerdo", comentaba el ingenioso reverendo Sidney Smith mientras observaba a dos mujeres discutiendo a gritos desde sus ventanas a ambos lados de la calle Edimburgo, "están argumentando desde premisas diferentes". Y es que habitamos, como le gusta repetir a Michael Thompson, un mundo de "certezas contradictorias" (Schwarz y Thompson, 1990).

Cada una de nuestras culturas, al "recordar" el pasado desde sus experiencias, sus convicciones profundas, sus premisas distintivas, crea una historia que inevitablemente contradice 
las que generan las otras. Y Williams nos avisó de que no podemos tratar los desacuerdos entre los relatos "simplemente como si ofrecieran representaciones en diferentes escalas o con diversos grados de resolución", que, aunque no quepa superponer sin más, "se pueden reconocer como representaciones igualmente aceptables de la escena" (Williams, 2006, pp. 248-249). No es así. Sencillamente, para cada uno de nosotros esas representaciones del pasado no son "igualmente aceptables", y esto es algo que, sin duda, coloca al profesor de historia en una posición molesta. El relativismo, ya lo dije, es un conocimiento incómodo. ¿Por qué diablos voy a llevar al aula las historias que se cuenta la cultura individualista sobre la "revolución industrial", de Hayek a McCloskey, si el que tiene sentido para mi es el relato de ese otro linaje que vincula a Marx y Engels con Schor? La respuesta es, por supuesto, que deberé hacerlo porque, si me tomo en serio el relativismo (y no se lo aplico sólo al discurso de los otros), tendré que acordar necesariamente con Bohr que cada relato contiene una "verdad profunda": que recoge datos de una experiencia concreta, parcial y "sesgada", pero valiosa, y destila por ello una porción de sabiduría que los otros no captan. Cada uno de ellos, además, expresa el modo en que "una parte significativa de la población cree que deberíamos vivir unos con otros y con la naturaleza" (Thompson, 2008, p. 25). De modo que, si quiere convertir realmente la enseñanza de la historia en un foro para la formación de la ciudadanía democrática, lo que le corresponde hacer al profesor es llevar al aula esos relatos contradictorios. Pero, ¿cómo debería hacerlo? ¿Cómo debería situarse frente a ellos?

\section{La "didáctica de la ciencia"}

El grueso de quienes se dedican profesionalmente a la investigación de la didáctica de la disciplina abomina del que identifiqué al comienzo de este artículo, amparándome en Savater, como el sentido secular de la transmisión de los saberes de la comunidad sobre el pasado. Les repugna concebir el aula como un receptáculo de relatos cargados de morales y enseñanzas políticas y apuestan en cambio por levantar de nuevo la bandera de Rafael Altamira para repetir con él que la historia, como disciplina científica, debe ejercer en las aulas de "educadora de la inteligencia" (Cuesta, 1998, p. 123). Desde luego, si definimos la ciencia, sin más, como "investigación sistemática y rigurosa" (McCloskey, 2010) nada de lo que apunté arriba sobre el escepticismo filosófico contemporáneo impide que describamos a la mejor historia académica de ese modo ${ }^{11}$. También debería resultar evidente que una cosa es recordar que las explicaciones que las ciencias sociales pueden ofrecernos no son de esas que, como quería Runciman, "no hay más remedio que aceptar", y otra muy distinta decir que no hay explicaciones mejores y peores.

Si alguien nos dice que $A$ es la causa de $B$, tendrá que presentarnos a continuación una evidencia creíble de la presencia de A. Luego deberá "explicar la explicación": eliminar las "cajas negras", los saltos infundados entre las causas postuladas y las supuestas consecuencias, aclarando el modo en que las acciones "razonables" de los individuos o los grupos conducen de A a $B$ y haciendo inteligible el resultado. A este tipo de cosas es a lo que querrían que se dedicasen las clases de historia la mayoría de los expertos en didáctica: a enseñar a los jóvenes a evaluar la evidencia que sostiene las afirmaciones de hecho y los mecanismos que se postulan para conectar causa y efecto, a enseñar a exigir que las conexiones se aclaren y los modos de hacerlo, a descubrir y contrastar las ideas sobre los seres humanos que subyacen a todas las explicaciones, a distinguir lo que podría ser una causa necesaria de lo que sería "suficiente", etc.

¿Acaso cabe negar el valor de la enseñanza práctica de estos procedimientos y métodos de

$11 \mathrm{McCloskey} \mathrm{ha} \mathrm{defendido} \mathrm{en} \mathrm{varias} \mathrm{ocasiones} \mathrm{que} \mathrm{la} \mathrm{historia} \mathrm{es} \mathrm{en} \mathrm{general} \mathrm{una} \mathrm{disciplina} \mathrm{más} \mathrm{"científica"}$ que la economía, la orgullosa reina de las ciencias sociales, y que los economistas tienen mucho más que aprender del trabajo de los historiadores que a la inversa. Claro que si uno utiliza los criterios de Elster (2007) para definir a la ciencia, mucho más exigentes, todas las ciencias sociales quedan fuera sin remisión. En cualquier caso, la peor parada sigue siendo la economía, la más contaminada por lo que Elster describe como el "oscurantismo duro" de la modelización matemática y la obsesión cuantitavista. 
la historia, "como disciplina científica", en el aula? Por supuesto que no. Todo ello forma parte del estudio de la retórica de la ciencia: el arte de argumentar bien y evaluar los argumentos ajenos, limitado, o guiado, por el respeto a las virtudes de la verdad que inspiran la labor científica: la precisión y la sinceridad. Si esto no es esencial para la formación ciudadana en una democracia sana, probablemente nada lo sea. Lo sería desde luego si acordásemos que, aunque haya más una historia verdadera que contar sobre el pasado (al menos, como dije arriba, desde el momento en que la historia adquiere sentido, contiene "lecciones" para el presente y, por lo tanto, valor educativo, y esta es la verdad del relativismo que debemos diseminar), hay también muchas que son simplemente falsas. Conviene, por lo tanto, que los jóvenes aprendan a hacer preguntas a esas historias, a evaluar su sinceridad (su manejo de la "evidencia") y su precisión (la calidad de sus "explicaciones"). El mundo digital está plagado de relatos conspirativos realmente fascinantes frente a los que no conviene quedarse paralizado, y hay filosofías de la historia más o menos grandilocuentes, de gran alcance, que también resultan fascinantes, pero que ocultan cómo funcionarían los grandes procesos que describen (protagonizados por naciones, razas o clases con destinos manifiestos). Historias que rehúsan responder cuando se les pregunta u ofrecen respuestas que nunca pasarían la prueba de la retórica de la ciencia. Y una democracia sana depende, entre otras cosas, de una ciudadanía capaz de apreciar y vigilar el respeto a las fronteras que separan la autoridad del poder desnudo o, lo que es lo mismo, las buenas razones (aunque no se compartan) de la fuerza y la manipulación.

Hay algunas perspectivas pedagógicas que parecen creer que toda autoridad, en el aula y en la sociedad amplia, es en realidad sólo poder y manipulación, de modo que no tendría sentido distinguir "entre las fuerzas que son argumentaciones y las que no lo son, como la diferencia entre escuchar y ser golpeado" (Williams, 2006, p. 20). Claro que si imaginamos que siempre que los otros nos hablan, contándonos historias, en realidad nos golpean en la cabeza con un discurso de poder frente al que sólo cabe someterse o resistir y contraatacar con otro discurso equivalente, no sería raro que termináramos golpeándonos de verdad ( $\mathrm{y}$ entonces sí apreciaríamos la diferencia). Pero lo que ocurrirá seguro es que no aprenderemos nunca nada y que nunca mejorará la calidad de nuestro debate público. De modo que sí: conviene estudiar y practicar en el aula las retóricas de la ciencia, la evaluación de la evidencia, el arte de la buena explicación y la buena argumentación. Y continuar elaborando esos ejercicios debería ser, entonces, la cuarta y última tarea de la didáctica de la historia.

\section{Las historias y el ermitaño}

Está claro, sin embargo, que lo que no hace el programa de la "didáctica de la ciencia" es ofrecernos razones para enseñar y estudiar historia. Si de lo que se trata (y de eso exactamente se trata) es de enseñar a argumentar y a evaluar argumentos, a explicarnos, exigir explicaciones y valorar su credibilidad, el profesor encontrará ideas mucho más interesantes leyendo a Boudon o a Elster, que escriben en el quicio de la sociología y la filosofía, o a Toulmin, que es filósofo, que rebuscando en los soporíferos tratados sobre los métodos de la historia (o de la Historia con mayúsculas, si se prefiere). Lo que implica, por supuesto, que la enseñanza de los métodos de la "disciplina científica" para "educar la inteligencia" de los jóvenes ofrece una base terriblemente endeble para defender el valor del estudio de la historia en las escuelas. La única demarcación significativa a este respecto es la que separa a las ciencias sociales de las naturales, así que no deberíamos perder ni un minuto más elucubrando sobre los peculiares valores educativos del "método histórico". Esto no quiere decir que no quepa encontrar diferencias en las retóricas de cada una de las ciencias sociales. Podríamos muy bien decir, por ejemplo, que la economía tiende más a emplear datos estadísticos como "evidencia", mientras que la historia, según Judt (2010, p. 23), "enseña mediante ejemplos", aunque las dos puedan hacer, y hagan, ambas cosas. Lo que sí quiere decir es que esas diferencias no pueden justificar en ningún caso la presencia en las escuelas de una asignatura de historia. 
Si lo anterior es cierto, podríamos llegar a pensar que el grueso de los expertos en didáctica no quiere en realidad enseñar historia. Que ese grupo es en la práctica la voz más articulada y coherente de la cultura individualista en el debate que nos ocupa, porque es esa cultura la que contiene más declaraciones hostiles a la transmisión de relatos morales o narraciones "identitarias" de cualquier tipo $^{12}$. Pero la cultura individualista tiene sus propios relatos morales que contar, y seguramente resulte más apropiado suponer que el "atractor" profesional de los expertos en didáctica les lleva simplemente, en expresión de Brighouse (2005, p. 2), a centrarse "en los intereses de los jóvenes frente a lo de la sociedad más amplia", e imaginarse como baluartes imparciales de la autonomía del alumno. En la jerga de la teoría cultural, podríamos decir que aspiran a la posición del "ermitaño": aquél que minimiza las transacciones mundanas para liberarse de sus coacciones. Cada una de las culturas construye el tiempo de un modo peculiar, interpreta el pasado y proyecta su estructura temporal distintiva hacia el futuro, prometiendo a quienes las constituyen que conseguirán bienes materiales, o estatus, o seguridad, o evitarán catástrofes y vivirán vidas más plenas, más humanas, si atienden a las enseñanzas de sus historias. Cada una es, a su manera, una estructura coercitiva. Y dado que la elusión de las relaciones sociales coercitivas es el fundamento de la vida autónoma, el ermitaño tendrá que desconectarse de todas esas estructuras temporales para estabilizar su vida alrededor de lo que él prefiere (Thompson, 2008). El ermitaño, en el aula, también insistiría en la autonomía, enseñaría, puestos a enseñar algo, la didáctica de los métodos de la ciencia y evitaría enseñar historia. No tiene razones para enseñarla. Quienes las tienen son los que viven atrapados en las estructuras coactivas de "la sociedad amplia": el jerarquista preocupado por la decadencia de la comunidad nacional o de los valores tradicionales, el individualista que quiere ilustrar a los jóvenes sobre los beneficios del libre comercio, las infinitas potencialidades de la creatividad humana y los peligros del "gobierno grande", o el igualitarista que aspira a convencerles de que deben implicarse en la reparación de las injusticias del pasado o en evitar la deriva catastrófica del capitalismo.

\section{Concluyendo: tres maestros de historia en uno}

En el contexto "moderno" podríamos muy bien describir el sentido secular de la enseñanza de la historia (y con más motivo cuanto más se aproxime la situación de la comunidad a lo que Dahl (2009) denominó "hegemonía cerrada", en la que la voz de una cultura apaga todas las otras) como un mero adoctrinamiento. Un adoctrinamiento que utiliza, con mayor o menor intensidad y mejor o peor conciencia, el alibí de la ciencia, la coartada de la estructura narrativa del pasado "propiamente dicho". En el contexto "posmoderno", asumidas las noticias incómodas que trae consigo el relativismo, deberíamos proponernos rediseñarlo como una combinación del viejo adoctrinamiento (en las "verdades" que enseña una "historia común" elaborada reflexivamente) y la incitación (con el ramillete de historias "verdaderas" y contradictorias que recogemos de la sociedad y llevamos al aula) a la reflexión moral y política, dialógica y siempre inclusa, sobre la variedad de nuestras convicciones.

El profesor, pues, como predicador, pero también como provocador, porque intenta provocar con sus historias el interés en nuestros debates públicos, crea inquietud, incita a la discusión. Hasta cierto punto, las dos figuras pueden equipararse a las que se dibujan cuando se oponen maestro "tradicional" (predicador) y maestro "crítico" (provocador). Pero sólo hasta cierto punto, porque hay

12 Para ofender lo menos posible con las etiquetas, conviene señalar que las culturas que vengo mentando no son ni ideologías políticas ni "tipos de personalidad": las primeras "articulan" valores y razones de diferentes culturas y los individuos tenemos varios "yoes", de modo que podemos adherirnos a una u otra de ellas en las diferentes esferas sociales en que participamos (votamos socialista, defendemos valores individualistas en el trabajo, adoptamos posturas jerárquicas con nuestros hijos, y así sucesivamente). Así que tal vez sería mejor decirnos "dividuos", porque no hay nada socialmente "indivisible" en nosotros. El "individuo" indivisible, capaz de conseguir una plena coherencia entre sus compromisos culturales en todos los ámbitos, sería probablemente lo que llamamos un fanático. 
al menos dos diferencias importantes. La primera es que en la propuesta que he pergeñado ambos son, en realidad, dos semblantes de la misma persona. La segunda, que no podemos ver al maestro "crítico" como baluarte de la historia "crítica" frente al discurso omnímodo del poder, porque hay más de una historia crítica. Las historias del libertario y el hombre de orden pueden contener alegatos tan contundentes como los del viejo socialista o el joven "altermundista" contra lo que ellos entienden que es el "pensamiento único" o el "discurso hegemónico." El profesor, por lo tanto, debería hacer un esfuerzo por desprenderse de sus compromisos mundanos si no queremos que el conocimiento incómodo del relativismo sea una simple coartada para embestir al otro y la enseñanza crítica de la historia un mero adoctrinamiento inverso.

Es aquí cuando entra en escena, finalmente, el ermitaño: el hombre que busca la autonomía. En nuestro contexto, es el profesor que enseña la retórica de la ciencia como "educadora de la inteligencia". Douglas escribió en cierta ocasión que "si hablamos todos a coro" sobre nuestra libertad de pensamiento es, sencillamente, porque las instituciones están pensando por nosotros, creando la ilusión de que somos, cada uno, un librepensador (Douglas, 1996, p. 140). Puede que tuviera razón, pero la aspiración a dotar a los jóvenes de las herramientas para pensar por sí mismos, como individuos autónomos, seguiría siendo, en cualquier caso, un pilar básico del ideal docente. De modo que el ermitaño debería ser el tercer semblante del maestro de historia. Con cualquiera de los tres por separado, el profesor de historia tendría mala cara. El predicador, si lo dejamos suelto, ya sabemos lo que haría: adoctrinar al rebaño en el canon de la historia oficial; el provocador, librado a sí mismo, nos dejaría sin los puntos de referencia compartidos que consideramos necesarios para la vida en comunidad y se convertiría él mismo en un predicador disidente, más o menos airado; el ermitaño, con su olímpico desprecio por los relatos ideológicos de las culturas, podría dedicarse a practicar métodos y entrenar mentes, pero no encontraría razones para enseñar historia. En realidad, cada uno necesita a los otros dos, y los tres son necesarios si queremos componer una figura digna del profesor de historia. Es verdad que pedimos demasiado; que el profesor de historia, así descrito, es un animal fantástico que no vamos a encontrar en ninguna parte. Pero creo que deberíamos intentar parecernos lo más posible a esa criatura si queremos que la enseñanza de la historia sea auténticamente "relevante" para la comunidad democrática y sus futuros ciudadanos.

\section{Bibliografía}

Brighouse, B. (2005). On Education. Londres: Routledge.

Cuesta, R. (1998). Clío en las aulas. La enseñanza de la Historia en España, entre reformas, ilusiones y rutinas. Madrid: Akal.

Cuesta, R. (2007). Los deberes de la memoria en la educación. Barcelona: Octaedro.

Dahl, R. A. (2009). La poliarquía : participación y oposición. Madrid: Tecnos.

Danto, A. C. (1989). Historia y narración: ensayos de filosofía analítica de la historia. Barcelona: Paidós/l.C.E. de la Universidad Autónoma.

Dening, G. (1996). Performances. Carlton South, Vic., Australia: Melbourne University Press.

Donoghue, F. (2008). The last professors: the corporate university and the fate of the humanities.

New York: Fordham University Press.

Douglas, M. (ed.) (1982). Essays in the Sociology of Perception. Londres: Routledge.

Douglas, M. (1996). Cómo piensan las instituciones. Madrid: Alianza Editorial.

Douglas, M. (2003). Being fair to hierarchists. University of Pennsylvania Law Review, 151, 4, 134970.

Drucker, P. F. (1993). La sociedad poscapitalista. Barcelona: Apóstrofe.

Elster, J. (2007). Explaining Social Behavior: More Nuts and Bolts for the Social Sciences. Cambridge: Cambridge University Press.

Evans, R. J. (1997). In Defence of History. Londres: Granta Books.

Farrell, F. B. (1996). Subjectivity, Realism and Postmodernism. The Recovery of the World in Recent Philosophy. Cambridge: Cambridge University Press. 
Ferrater Mora, J. (1965). Diccionario de Filosofía (5a ed.). Buenos Aires: Editorial Sudamericana. Fueter, E. (1953). Historia de la historiografía moderna. Buenos Aires: Nova (edición original de 1911)

Hobsbawm, E. (1998). Sobre la historia. Barcelona: Crítica.

Hollis, M. (1998). Filosofía de las ciencias sociales. Barcelona: Ariel.

Iggers, G. G. (1997). Historiography in the Twentieth Century. From Scientific Objetivity to the Postmodern Challenge. Hanover, New England: Wesleyan University Press.

Judt, T. (2008). Sobre el olvidado siglo XX. Madrid: Taurus.

Judt, T. (2010). El refugio de la memoria. Madrid: Taurus.

Little, D. (1991). Varieties of Social Explanation. Introduction to the Philosophy of Social Science. Boulder, Col.: Westview Press.

McCloskey, D. N. (2001). Getting it Right, or Left: Marxism and Competition. Eastern Economic Journal, 27 (4), 515-20.

McCloskey, D. N. (2010). Bourgeois dignity: why economics can't explain the modern world. Chicago: University of Chicago Press.

Nussbaum, M. C. (2010). Sin fines de lucro. Por qué la democracia necesita de las humanidades. Madrid: Kazt Editores.

Postman, N. (1999). El fin de la educación. Barcelona: Octaedro.

Runciman, W. G. (1999). El animal social. Madrid: Taurus.

Savater, F. (1997). El valor de educar. Barcelona: Ariel.

Schwarz, M. y Thompson, M. (1990). Divided We Stand. Redefining Politics, Technology and Social Choice. Hemel Hempstead: Harvester Wheatsheaf.

Thompson, M. (2008). Organising \& disorganising: a dynamic and non-linear theory of institutional emergence and its implications. Axminster, U.K.: Triarchy Press.

Thompson, M., Ellis, R. y Wildavsky, A. (1990). Cultural Theory. Boulder, Colorado: Westview Press.

Verweij, M. (2007). Towards a theory of constrained relativism: Comparing and combining the work of Pierre Bourdieu, Mary Douglas, Michael Thompson, and Alan Fiske. Sociological Research Online, 12 (6) 7. Recuperado de www.socresonline.org.uk

Williams, B. (2006). Verdad y veracidad. Barcelona: Tusquets.

Woolf, D. (2011). A global history of history. Cambridge: Cambridge University Press. 



\section{Panta Rei}

PANTA REI es una revista digital de investigación orientada a la Historia y otras ciencias afines. Su principal objetivo es la transmisión del conocimiento científico, dando una oportunidad también a los jóvenes investigadores que quieren abrirse camino en el estudio de las ciencias humanas y sociales. Se compone de estudios originales relacionados con la disciplina histórica así como su didáctica y difusión. Las diferentes secciones que componen la revista son: artículos de investigación, entrevistas a profesionales, recensiones de monografías de actualidad y crónicas de congresos o eventos científicos relevantes.

Todos los artículos publicados son objeto de un proceso de revisión a cargo de un mínimo de dos evaluadores, que se consideran expertos en el ámbito temático del artículo propuesto. Nuestro deseo es poder ofrecer unos contenidos rigurosos, de calidad y de interés.

EI CEPOAT (Centro de Estudios del Próximo Oriente y la Antigüedad Tardía de la Universidad de Murcia) es la institución encargada de la coordinación y gestión de la revista, desde donde anualmente se lanzará la convocatoria para aquellos que estén interesados en publicar sus trabajos, siempre relacionados con la Historia, Arqueología, Historia del Arte, Didáctica de las Ciencias Sociales, etc.

PANTA REI is a digital journal focused on History and other sciences related to it. Its main objective is the transmission of scientific knowledge by giving also an opportunity to young researchers who want to make their way in the study of human and social sciences. It is composed by original studies related to History, as well as its didactics and promotion. The different sections of this journal are: research articles, interviews to professionals, recensions on monographs about current issues and reports about congresses or relevant scientific events.

All the articles published are subject to a revision process carried out by a minimum of two reviewers who are considered to be experts in the field of the article proposed. Our wish is to offer rigorous contents with quality and being of interest to the reader.

CEPOAT (Centre of Studies of the Middle East and Late Antiquity of the University of Murcia) is the institution in charge of the coordination and management of this journal. This is the centre from where the call for papers will be launched for all the people interested in publishing their papers, always related to History, Archeology, Art History, Didactics of the Social Sciences, etc. 


\section{Normas de Publicación}

El autor se compromete a enviar trabajos originales, que no se encuentren publicados en otras revistas ni en otros idiomas. Así mismo, el mismo artículo no podrá ser presentado en otras revistas mientras dure el proceso de evaluación.

\section{Envío y presentación de originales}

Los artículos se enviarán exclusivamente a través del correo electrónico a la dirección pantarei@um.es. Los textos serán enviados en formato DOC y las imágenes en formato JPEG o TIFF, y con un tamaño mínimo de 2000 px. Éstas no aparecerán incorporadas en el texto, sino enviadas en archivo aparte y correctamente numeradas según su posición en el texto. Junto al trabajo, se rellenará y enviará un documento aparte en el que se especifiquen los datos del autor siguiendo el modelo disponible en la página Web de la revista.

Para la redacción de los trabajos se tendrá en cuenta el Manual de la American Psychological Association, en su sexta edición. La extensión máxima de los trabajos será de 30 páginas. La tipografía será Arial 11, con interlineado sencillo y sin espacio alguno entre párrafos. El texto deberá ir justificado a ambos márgenes y sin sangría en los primeros párrafos. Los márgenes serán de $2,50 \mathrm{~cm}$. En los casos en los que fuera necesario incorporar notas, éstas irán a pie de página, enumeradas consecutivamente, con tipografía Arial 10, interlineado sencillo y justificadas a ambos márgenes.

Una información más detallada se encuentra disponible en la página http://www.um.es/cepoat/ pantarei.

\section{Proceso de valoración y evaluación}

Una vez recibidos los trabajos, la Revista realizará una primera valoración. Si el trabajo enviado se ajusta a las normas de presentación propuestas, la temática es coincidente con la línea editorial de la revista y posee la calidad científica necesaria, será remitido al consejo asesor para una primera evaluación. Si no es así en este primer paso se puede rechazar directamente los documentos que incumplan claramente la línea editorial.

Será el Consejo Asesor quien indique a la revista la originalidad, relevancia, estructura, redacción, aparato bibliográfico, etc. del trabajo enviado y, para ello, se designará a dos revisores expertos externos que evaluarán cada uno de los trabajos, que pueden formar parte (o no) de este Consejo Asesor. La selección de los revisores se ajustará a la temática y características metodológicas del trabajo. El nombre y filiación de los autores serán eliminados del trabajo para su revisión, así como los revisores actuarán de manera anónima y confidencial.

Los revisores deberán rellenar un informe de evaluación que centrará su atención en aspectos tales como características formales, originalidad y novedad de los trabajos, relevancia de las propuestas y los resultados, calidad metodológica y validez científica.

Una vez terminado el proceso se decidirá la aceptación o no de los mismos y su publicación en el número que sea pertinente, así como las modificaciones susceptibles de ser realizadas para su final publicación. Dicha notificación se enviará únicamente por correo electrónico, en un plazo máximo de seis meses. 


\section{Publishing rules}

The author is committed to submit original papers not having been published in other reviews or in other languages. In this way, it is not allowed for the same paper to be presented in other reviews during the evaluation process.

\section{Submission and presentation of originals}

The articles will be exclusively submitted by email to pantarei@um.es. The texts will be submitted in DOC format and the images in JPEG or TIFF format, and with a minimum size of 2000 px. Images will not be integrated in the text but sent in another file and properly numbered according to their position in the text. Attached to the paper, a document will be filled out and sent where the author's data will be specified following the model available on the website.

The sixth edition of the Manual of the American Psychological Association will be taken into account for the writing of the papers. The length of the papers must not exceed 30 pages. Typography will be Arial 11 , with simple line spacing and no space between paragraphs. The text must be justified on both margins without indentation in the first paragraphs. Margins size will be $2.50 \mathrm{~cm}$. Where it could be necessary the incorporation of notes, they will be at the bottom of the page, consecutively numbered with typography Arial 10, simple line spacing and justified on both margins.

More detailed information is available on the website: http://www.um.es/cepoat/pantarei.

\section{Examination and assessment process}

The Journal will submit the papers to a first examination once received. If the paper follows the presentation guidelines, the subject agrees with the editorial line of this journal, and possess the scientific quality required, it will be sent to the advisory council for a first assessment. If not, the documents which clearly fail to complete the editorial line may be rejected straightaway in this first step.

The Advisory Council will indicate the originality, relevance, structure, writing, bibliography, etc. of the text to the journal; for this purpose, two outside experts will be designated to review the papers; these experts can be (or not) part of this Advisory Council. The selection of the experts will adjust to the subject and methodological characteristics of the paper. Name and affiliation of the author will be eliminated from the text for its review, in this way experts will act anonymously and confidentially.

The experts will fill out an assessment report which will focus on aspects such as formal characteristics, originality and novelty of the papers, relevance and results of the proposal, methodological quality and scientific validity.

Once the process is finished, the acceptance or not of the papers and its publication in the corresponding edition will be decided, as well as the modifications that may be done for its final publication. This notification will be sent by email within 6 months maximum. 

